\title{
Anterior cervical myelopathy in the early postoperative period
}

Muñoz Corsini L. MD, García del Valle S. MD, Gonzalez A. MD, Galindo S. MD, Porras M. MD

Purpose: The onset of anterior cervical myelopathy in the early postoperative period is an unusual complication after cardiac surgery without extracorporeal circulation in which haemodynamic stability was maintained. We report a patient who developed anterior cervical myelopathy after cardiac surgery.

Clinical features: A 53-yr-old man with no serious associated medical problems underwent cardiac surgery without extracorporeal circulation to repair a ruptured left ventricle. Haemodynamic stability was maintained throughout the procedure but the patient developed flaccid paraparesis and dissociated sensory loss, three hours later. Early recognition of the clinical picture and prompt initiation of steroid treatment facilitated a successful outcome. The definitive diagnosis was based on magnetic resonance findings days after surgery.

Conclusion: The onset or aggravation of neurological symptoms in the postoperative period may be avoided by thorough search for medullary pathology in the patient's background and by using particular care when performing manoeuvres during the perioperative period, not only to ensure haemodynamic stability, thus preserving medullary perfusion, but also to avoid mechanical compression of a spinal segment.

Objectif : Lapparition à la période postopératoire d'une myélopathie cervicale anténeure constitue une complication inusitée pour une intervention cardiaque sans circulation extracorporelle (CEC) et sans altération de la stabilité hémodynamique. Nous rapportons le cas d'un patient victime d'une myélopathie cervicale après une chirurgie cardiaque.

Éléments cliniques : Un homme de 53 sans problèmes médicaux associés importants a subi une chirurgie sans CEC pour la réparation d'une rupture ventriculaire gauche. La stabilité hémodynamique a été maintenue pendant l'intervention mais le patient a développé une paraparésie flasque et une perte de sensibilité dissociée trois heures après l'intervention. La reconnaissance précoce du tableau clinique et l'initiation rapide de la corticothérapie a permis une évolution favorable.

Conclusion : À la période postopératoire, l'apparition et l'aggravation de symptômes neurologiques peuvent être évitées par la recherche méticuleuse d'une pathologie médullaire préalable. Pendant la période périopératoire, il faut assurer la stabilité hémodynamique et éviter la compression mécanique du rachis.

From the Department of Anesthesia, Clínica Puerta de Hierro \{C/San Martín de Porres, 4; 28035 Madrid, España) Address correspondence to: Lourdes Muñoz Corsini, C/Migucl Fluiters, 35, 29, 19001, Guadalajara, España; Phonc: 949-253026. Accepted for publication May 12, 1997. 
$\mathrm{T}$ HE onset of new spinal neurological deficits or the aggravation of existing defects is a rare complication of regional anaesthesia ${ }^{6}$ and is reported to have an incidence between $l$ to $14 \%$ after some procedures requiring general anaesthesia. ${ }^{7}$ Published cases mostly involve replacement of the thoracic aorta, ${ }^{7,8}$ the rest are attributed to manoeuvres that may destabilize the cervical column such as laryngoscopy or orotracheal intubation in patients with known pathology in this area. ${ }^{4,8-11}$

We present a case of reversible anterior cervical myclopathy that developed in the immediate postoperative period after cardiac surgery in which the first signs of cervical pathology appeared during right internal jugular vein cannulation prior to induction of anaesthesia.

\section{Case report}

A 53-yr-old man with no relevant medical history was admitted to our hospital with a very large acute anterior myocardial infarction. There was no evidence of revascularization. He was treated with rtPA (recombinant tissue plasminogen activator) and sodium heparin (5000 units $i v$ followed by infusion at $1000 \mathrm{u} \cdot \mathrm{hr}^{-1}$ ) and atenolol, enalapril, nitrates, ranitidine and diazepam were added. The patient developed acute lung oedema, arterial hypotension and low cardiac output that required occasional catecholamines $(2-4$ $\mu \mathrm{g} \cdot \mathrm{kg} \cdot \mathrm{min}^{-1}$ dopamine) to produce a favourable outcome. Echocardiography revealed a slightly dilated left ventricle with a hypokinetic septum and a large anteroseptal akinetic zone in addition to mild pericardial effusion. Thus, heparin was withdrawn and antiaggregation therapy with aspirin (500 $\mathrm{mg} \mathrm{q6h,po)} \mathrm{as}$ well as angiotensin-converting enzyme inhibitors (ACEI) (Captopril 6'25 mg q8h, po) were begun. During his stay in the hospital, the patient complained of spontaneous non-radiating interscapular pain which is partially controlled with non-steroidal antiinflammatory drugs (NSAIDs) (Ibuprofen $400 \mathrm{mg} \mathrm{q} 6 \mathrm{~h}, \mathrm{po}$ ). Two days later, cardiac tamponade developed with a severely reduced ejection fraction (EF), by echocardiography, which revealed an apical thrombus. With a suspicion of left ventricle (LV) rupture, it was decided that emergency surgery was indicated. The patient was conscious and well-oriented upon entering the operating room, and a superficial neurological exploration revealed no abnormality. The initial interscapular ache persisted. The systolic/diastolic arterial pressures (AP) were $130 / 70 \mathrm{mmHg}$ and all the preoperative laboratory analyses, including coagulation tests, were normal.
After premedication with $2 \mathrm{mg}$ midazolam $i v$, standard monitoring for cardiac surgery was begun, including $\mathrm{CV}_{5} \mathrm{ECG}$ lead, $\mathrm{S}_{\mathrm{p}} \mathrm{O} 2$, invasive $\mathrm{AP}$ in right radial artery and uretral catheter, as well as cannulation of the right internal jugular vein. For this, the patient's head was rotated towards the left, a manoeuvre that made the patient cry out in response to sudden, severe, piercing nonradiating cervical pain that was relieved by placing his neck in a neutral position. There were no other neurosurgical symptoms. Therefore, we continued to cannulate the vein in this position without further consequences. Routine preoperative airway evaluation caused no pain and an easy orotracheal intubation was expected. Anaesthesia was induced with $50 \mathrm{mg}$ ketamine, $3 \mathrm{mg}$ midazolam and $0.5 \mathrm{mg}$ fentanyl and relaxation was achicved with 70 $\mathrm{mg}$ succinylcholine to facilitate tracheal intubation. Laryngoscopy and intubation were event-free, and a complete view of the vocal cords was obtained on the first attempt. Once the patient was asleep, an intrascapular pillow was positioned to facilitate the surgical approach which left the inferior cervical region flexed with hyperextension of the superior cervical segments. Anaesthesia was maintained with $\mathrm{O}_{2}$ /air and isoflurane $0.5 \%$, fentanyl ( $1 \mathrm{mg}$ total dose) and pancuronium (10 $\mathrm{mg}$ total dose) with controlled pulmonary ventilation. Surgery took $60 \mathrm{~min}$ to repair the myocardial defect with a pericardial patch, without the need for extracorporeal circulation. The patient was haemodynamically stable with normal blood gases and temperature between $35^{\circ}$ and $36^{\circ} \mathrm{C}$. Two units of whole blood were transfused.

After surgery, he was taken in a haemodynamically stable state and with his trachea intubated, to the recovery unit, and the trachea was extubated three hours later. Then, the patient complained of extreme weakness of both lower extremities. Examination revealed flaccid paraparesis affecting the toes of the right foot; temperature and pain sensations were preserved. Examination of the upper extremities was normal. The patient was conscious and well-oriented and the cranial nerve examination was normal. In view of this somewhat uninformative exploration and the recent tracheal extubation, the possibility that was caused by a response to stress ${ }^{12}$ was considered and it was decided to examine the patient repeatedly. Five hours later, flaccid paraplegia was evident and dissociated thermal sensation developed in the right leg. In addition, paraesthesia and distal motor weakness in both upper extremities appeared. In view of the clinical progression, a neurologist found him to be awake, well-oriented to language and superior functions preserved with normal cranial nerves. The 
motor deficit affected all muscular groups bilaterally, although it was more noticeable on the left. There was no evidence of amyotrophy or fasciculation. ${ }^{13}$

Superficial osteotendinous reflexes were diminished bilaterally and symmetrically, particularly the left knee reflex. The sensory level was bilateral at $\mathrm{C}_{7}$, although with more markedly impaired tactile sense on the right side, and decreased vibratory sense was detected in both lower extremities. Propioceptive sensitivity was preserved. Coordination was unevaluable. The bladder was catheterized and there was no evidence of relaxation of the anal sphincter. The rest of the physical examination, ECG and analyses were nomal, and the blood pressure was $100 / 60 \mathrm{mmHg}$.

In view of this a diagnosis of medullary ischemia at the $\mathrm{C}_{7}$ level was madc and treatment with steroids ( 30 mg. $\mathrm{kg}^{-1}$ methylprednisolone, iv bolus followed by an infusion of $5.4 \mathrm{mg} \cdot \mathrm{kg}^{-1} \cdot \mathrm{ht}^{-1}$ for $23 \mathrm{hr}$ ) was begun immediately.

The next day, neurological examination improved, although the weakness in the lower extremities persisted and the patient was unable to extend his fingers. For this reason, rehabilitation was initiated and it was decided to postpone confirmation of the diagnosis by nuclear magnetic resonance (MR) since this technique was not available at our centre. Over the following six days, neurological examination became normal except for a persistent sensory loss at $\mathrm{C}_{7}$ and paracsthesia on the backs of both hands, with exaggerated superficial triceps reflexes.

Fourteen days later, the patient was transferred to another centre for sagittal and axial MR images in $T_{\text {, }}$ and $T_{2}$-weighted sequences (Figures 1,2 ). This revealed correction of the physiological lordosis with a normal spinal canal and compression of the dural sac on the anterior aspect at the $\mathrm{C}_{5-6}$ level, where some disk pathology was identified. At this level, minimal medullary compression was detected as a small hyperintense intramedullary injury secondary to ischaemic damage caused by compression due to the disc pathology and surgery. A repeated MR study was recommended after a six-month interval.

The patient was discharged seven days later with no neurological symptoms.

\section{Discussion}

The anterior spinal artery syndrome is caused by ischaemic damage to the middle two thirds of spinal medulla, affecting mainly the lateral corticospinal and spinothalamic tracts. ${ }^{9,14,15,20}$ It is characterized by an acute phase of flaccid paraparesis or tetraparesis, altered sphincter function and dissociated sensory loss that progress to hyperreflexia and positive Babinsky

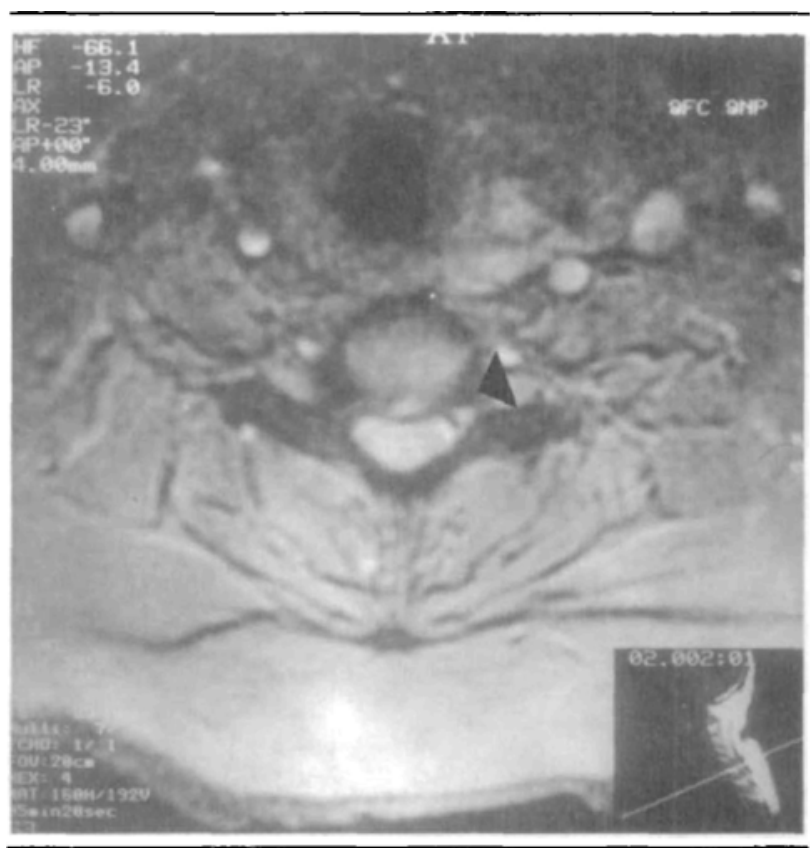

FIGURE 1 A disk lesion and compression of the dural sac on the anterior aspect at the $\mathrm{C}_{5.0}$

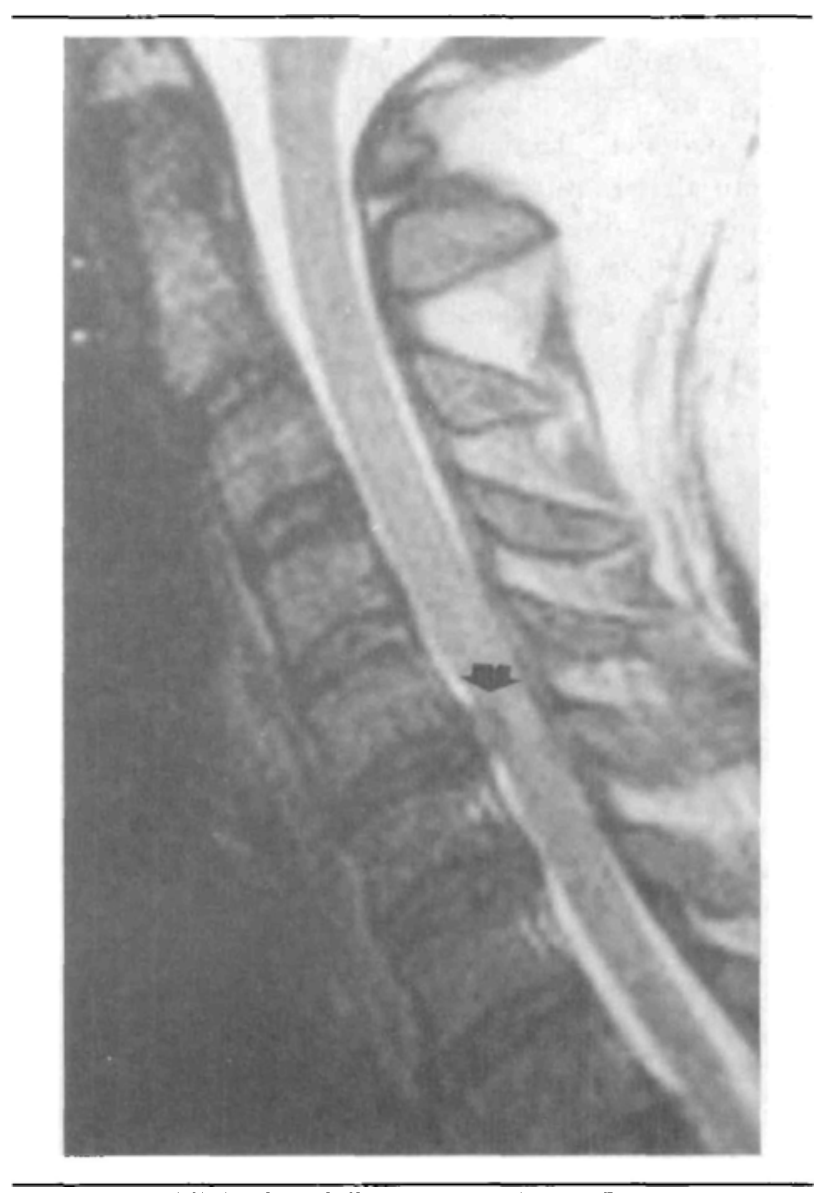

FIGURE 2 Minimal medullary compression at $\mathrm{C}_{5-\mathrm{s}}$. 
sign, generally bilateral. ${ }^{13,14}$ In our patient, the diagnostic suspicion and early and effective therapy were based on the recognition of these symptoms.

In the search for factors that diminish medullary pressure perfusion beyond the critical level, we examined procedures carried out during anaesthesia induction, that increase the cerebrospinal fluid (CSF) pressure by compression, ${ }^{1,8}$ involving the cervicothoracic zone which, in itself, is vulnerable, ${ }^{8,14-16}$ as well as events that compromise the local arterial pressure (hypotension, low cardiac output and hypoxemia), ${ }^{1,2,7,8}$ occurring during the perioperative period. Although during the days before surgery, the patient required catecholamines to treat hypotension and low cardiac output, he never presented signs of medullary ischaemia. Later, intraoperative haemodynamic stability was maintained continuously, with average arterial pressures $>50$ $\mathrm{mmHg}, 1,2$ although borderline arterial pressure can augment the injury caused by compression. ${ }^{1,8}$

With respect to this mechanism, the extreme rotation of the neck prior to cannulation of right internal jugular vein provoked the first symptom of cervical pathology in the form of painful radicular syndrome $e^{8,13}$ which led the anaesthetist to proceed with the patient's head in a neutral position, a posture that did not hinder the venous approach. ${ }^{17,18}$ As the pain disappeared when the neck position was changed and that it was not accompanied by other neurological symptoms, any possible injury went unnoticed. Any suspicion of cervical disease might have led to a change in the approach for intubation as there are reports of the presentation or aggravation of neurological deficits in patients with cervical pathology after undergoing laryngoscopy and tracheal intubarion $^{9,19-21}$ which provoke flexor and extensor movements in the cervical segments. ${ }^{10}$ Despite this, previous reports recommend a conservative attitude as it has not been demonstrated that extraordinary procedures (nasal intubation, fibroscopy, etc.) diminish the risk of medullary injury. ${ }^{9,10,21}$ Moreover, in our case, the lack of a history or clear signs of cervical pathology did not indicate the use of an intubation technique of greater risk to the patient in the attempt to obtain, a priori, limited benefits. The forced intraoperative position of the patient, with inferior cervical flexion and hyperextension of the superior cervical segments produced by the interscapular pillow for $60 \mathrm{~min}$, seems to have contributed to increasing the CSF pressure and ischaemia in the medullary segment adjacent to that previously injured. ${ }^{8}$ In view of the outcome, it would seem reasonable to avoid extremely forced posiotions of the cervical column in any patient with symptoms of cervical pathology. ${ }^{1,9,14}$ It is also reasonable to look exhaustively for cervical pathology in patients who are to undergo a surgical pro- cedure that implies a forced intraoperative position in that region. In addition, it is desirable to keep the arterial blood pressures within the values of autoregulation. ${ }^{1,2}$

The onset of spinal dysfunction has recently been reported in patients with cervical spondylosis during the administration of benzodiazepines and droperidol, probably because of a specific neurochemical effect in susceptible patients, even in the absence of hypoxia and hypotension. ${ }^{11}$ In our case, although possible, this circumstance seems improbable because the patient had been receiving diazepam po for several days and midazolam iv prior to monitoring without any neurological manifestation.

Currently, MR is the definitive diagnostic technique and is valuable up to $12 \mathrm{wk}$ after injury. $14,17,19,20$ In our patient, MR performed 14 days after surgery, confirmed the diagnosis.

In the course of any medullary lesion, the two main prognostic factors are the severity of the initial neurological disorder, ${ }^{14,22,23}$ where an incomplete injury with preservation of some motor or sensory function at the level of the lesion is likely favourable, $, 19,20$ and its aetiology, ${ }^{10,25}$ since infarction caused by medullary hypoperfusion is irreversible. ${ }^{2}$ These two factors together with early initiation of steroid therapy ${ }^{19-21,24,25}$ favoured the clinical course in our patient until he had completely recovered from the spinal neurological deficit.

\section{References}

1 Skouen JS, Wainapel SF, Willock MM. Paraplegia following epidural anesthesia. A case report and a literature review. Acta Neurol Scand 1985; 72: 437-43.

2 Singh $U$, Silver JR, Welply NC. Hypotensive infarction of the spinal cord. Paraplegia 1994; 32: 314-22.

3 Mills GH, Howell SJL, Richmond MN. Spinal cord compression inmediately following, but unrelated to, epidural analgesia. Anaesthesia 1994; 49: 954-6.

4 Woodall N, Huggins NJ, Jewkes DA. Postoperative paraplegia in a patient with an unsuspected dural arterio-venous malformation. $\mathrm{Br} \mathrm{J}$ Anaesth $1990 ; 64$ : 638-41.

5 Arbonés Arán E, Espinosa Soldevilla W, Gutiérrez de Simone JW, Molina Ros A, Ardevol Cuesta J. Anterior spinal artery syndrome and intradural anesthesia. (Spanish) Rev Esp Anestesiol Reanim 1987; 34: $221-4$.

6 Foster MR, Nimmo GR, Brown AG. Prolapsed intervertebral disc after epidural analgesia in labour. Anaesthesia 1996; 51: 773-5.

7 Stutesman JL, Houston JM, Wayne DA. Post-surgical ischaemic myelopathy. Paraplegia 1987; 25: 23-6.

8 Silver JR, Buxton PH. Spinal stroke. Brain 1974; 97 : 539-50. 
9 Albin MS. Spinal cord injury. In: Cottrell JE, Smith DS (Eds.). Anesthesia and Neurosurgery, 3rd ed. St. Louis: Mosby 1993: 713-43.

10 Sawin PD, Todd MM, Traynelis VC, et al. Cervical spine motion with direct laryngoscopy and orotracheal intubation. Anesthesioloy 1996; 85: 26-36.

11 Miller RA, Crosby G, Sundaram P. Exacerbated spinal neurologic deficit during sedation of a patient with cervical spondylosis. Anesthesiology 1987; 67: 844-6.

12 Laraki M, Orliaguet GA, Flandin C, Merckx J, Barrier $G$. Hysterical paraplegia as a cause of transient paraplegia after epidural anesthesia. Anesth Analg 1996; 83: 876-7.

13 Fisiopatología de la médula y de las raíces nerviosas. En Rábano Navas AD. Guión de fisiopatología del sistema nervioso. Artes Gráficas Benzal, SA. Univ. Alcalá de Henares. Madrid. 1980: 6-35.

14 Errea JM, Ara JR, Pina MA, Fayed N. Anterior spinal artery syndrome due to cervical disk protrusion. Diagnosis by magnetic resonance. (Spanish).

Neurología 1991; 6: 256-8.

15 Netter $F H$. Sistema nervioso. Anatomía y fisiología. Vascularización de la médula espinal. Colección CIVA de Ilustraciones Médica, 2nd ed. Ed Salvat, Barcelona, 1986. Tomo I-1:64-6.

16 Gillilan $L A$. Veins of the spinal cord. Anatomic details; suggested clinical applications. Neurology 1970; 20: $860-7$.

17 Taneichi H, Abumi K, Kaneda K, Terae S. Monitoring the evolution of intramedullary lesions in cervical spinal cord injury. Qualitative and quantitative analysis with sequential MR imaging. Paraplegia 1994; 32: 9-18.

18 Troianos CA, Kuwik RJ, Pasqual JR, Lim AJ, Odasso $D P$. Internal jugular vein and carotid artery anatomic relation as determined by ultrasonography.

Ancsthesiology 1996; 85: 43-8.

19 Chiles BW III, Cooper PR. Acute spinal injury. N Engl J Med 1996; 334: 514-20.

20 Hickey R, Sloan TB, Albin MS. Acure spinal cord trauma. In: Shoemaker WC (Ed.). Textbook of Critical Care, 3rd ed. Philadelphia, Pennsylvania: WB Saunders Company, 1995; 158: 1457-65.

21 Seingry DR. Cervical injuries-anaesthetic implications, monitoring and management. Baillière's Clinical Anaesthesiology 1987; 1: 459-76.

22 Fujinma $\Upsilon$, Nishi $\Upsilon$,Chiba $K$, Kobayashi K. Prognosis of neurological deficits associated with upper cervical spine injuries. Paraplegia 1995; 33: 195-202.

23 Toscano J. Prevention of neurological deterioration before admission to a spinal cord injury unit. Paraplegia 1988; 26: 143-50.

24 Kelly DF. Steroids in head injury. New Horiz 1995; 3 : 453-5.
25 Waring WP, Karunas RS. Acute spinal cord injuries and the incidence of clinically ocurring thromboembolic disease. Paraplegia 1991; 29: 8-16. 